Article

\title{
Preliminary Screening of Growth and Viability of 10 Strains of Bifidobacterium spp.: Effect of Media Composition
}

\author{
Zuzana Matejčeková ${ }^{1, * \mathbb{C}}$, Eva Vlková ${ }^{2}$, Denisa Liptáková ${ }^{3}$ and L'ubomír Valík ${ }^{1}$ (i) \\ 1 Department of Nutrition and Food Quality Assessment, Faculty of Chemical and Food Technology, \\ Slovak University of Technology, Bratislava, 81237 Radlinského 9, Slovak Republic; lubomir.valik@stuba.sk \\ 2 Department of Microbiology, Nutrition and Dietetics, Faculty of Agrobiology, Food and Natural Resources, \\ Czech University of Life Sciences, Prague, 16500 Kámycká 129, Czech Republic; vlkova@af.czu.cz \\ 3 State Institute for Drug Control, Bratislava, 82508 Kvetná 11, Slovak Republic; denisa.liptakova@sukl.sk \\ * Correspondence: zuzana.matejcekova@stuba.sk; Tel.: +421-2-59325-517
}

Received: 22 March 2019; Accepted: 24 April 2019; Published: 28 April 2019

\begin{abstract}
Lactic acid bacteria (LAB) alone or with special adjunct probiotic strains are inevitable for the preparation of specific functional foods. Moreover, because of their growth and metabolism, final products are preserved for a certain time. Thus, in this work, growth and metabolic activity of novel animal origin isolates and culture collection strains of Bifidobacterium spp. were investigated. The influence of milk media (reconstituted or ultra-high-temperature (UHT) milk), compared with synthetic modified Wilkins-Chalgren $(\mathrm{WCH})$ broth under aerobic conditions was investigated. All tested bifidobacterial strains $(n=10)$ were grown well $(1-2$ log colony-forming units $(\mathrm{CFU}) / \mathrm{mL}$ for $24 \mathrm{~h}$ at $37^{\circ} \mathrm{C}$ ) in all substrates and levels higher than $5 \log \mathrm{CFU} / \mathrm{mL}$ remained during the cold storage period. Generally, different substrates determined almost the same maximal population densities (MPD) after $24 \mathrm{~h}$ that range within the average values of $8.96 \pm 0.43 \log \mathrm{CFU} / \mathrm{mL}$, $8.87 \pm 0.52 \log \mathrm{CFU} / \mathrm{mL}$, and $8.75 \pm 0.54 \log \mathrm{CFU} / \mathrm{mL}$ in reconstituted milk, UHT milk, and WCH broth, respectively. After 28 days of storage, the $\mathrm{pH}$ levels in milk media and broth were reduced to $4.50-5.60$ and $4.60-4.90$, respectively, representing a decrease of $0.8-2.13$ units.
\end{abstract}

Keywords: Bifidobacterium spp.; fermentation; viability; shelf life; reconstituted milk

\section{Introduction}

Genus Bifidobacterium is one of the most beneficial probiotic microorganisms and one of the most predominant cultures in the human colon and breast-fed infants [1]. Until 2014, genus Bifidobacterium included 48 species and subspecies and this number is expected to increase [2]. Bifidobacterium is a genus of Gram-positive, catalase-negative, non-motile, and non-spore-forming bacteria. They are obligate, partly facultative anaerobes belonging to the Actinobacteria phylum, and are naturally predominant components of the intestinal microflora, presenting up to $20 \%$ of the fecal bacteria in adults and $80 \%$ in infants [3]. Properties of the strains belonging to the genus Bifidobacterium are host-dependent. The reported optimal temperature for the growth of human bifidobacterial strains is between $36^{\circ} \mathrm{C}$ and $38^{\circ} \mathrm{C}$ [2]; for species of animal origin, it is slightly higher $\left(41-43^{\circ} \mathrm{C}\right)$ and may be even as high as $49.5^{\circ} \mathrm{C}$, as shown for B. thermacidophilum [4]. There is also generally no growth below $20^{\circ} \mathrm{C}$ with the exception of B. psychroaerophylum, whose growth was reported at temperatures as low as $8^{\circ} \mathrm{C}$ [5]. The optimum $\mathrm{pH}$ for growth is in range of 6.0-7.0, which means that no growth takes place below 4.5 and above 8.5 [6].

Bifidobacteria exclusively catabolize hexoses through a characteristic metabolic pathway, involving fructose-6-phosphoketolase as the key enzyme, known as the fructose-6-phosphate pathway or the 
so-called bifid shunt. Generally, bifidobacteria preferably utilize mono- and disaccharides, while, within fermentation of glucose, some non-fermented strains were reported [7]. Some Bifidobacterium species are able to ferment lactose and are able to grow in milk such as B. animalis ssp. lactis. Thus, the fermentation ability of different substrates, including saccharides, their derivatives, and alcohols, is strain-specific [8]. Genus Bifidobacterium is a well-investigated group of beneficial microbes to human health. Within the food industry, if bifidobacteria are present in final products, due to the fact that they are obligate, partly facultative anaerobes, the presence of oxygen causes a decline in counts in final products during manufacture and storage. Therefore, it is important to study factors (e.g., presence of prebiotics, oxygen content in products) that affect the growth and viability of these beneficial bacteria in final products. Many factors were reported to affect the growth and survival of probiotic bacteria, including acid and hydrogen peroxide produced by yoghurt bacteria, oxygen content and oxygen permeation through the package, and the storage temperature $[9,10]$. In spite of the fact that bifidobacteria are considered to be strictly anaerobic, there are some species that are able to survive in the presence of oxygen [11]. Bifidobacterium animalis in a study of Lamoureux et al. [12] exhibited a high survival rate in prepared yoghurt, and inoculation of $7.4 \log$ colony-forming units (CFU)/g was sufficient to obtain counts $>6 \log \mathrm{CFU} / \mathrm{g}$ after 28 days of cold storage at $4{ }^{\circ} \mathrm{C}$. Havas et al. [13] reported that the fermentation process of soymilk resulted in a concentration of $8 \log \mathrm{CFU} / \mathrm{mL}$ in all tested bifidobacteria after $8-12 \mathrm{~h}$ with all strains viable up to the end of fermentation $(48 \mathrm{~h})$. Maintaining the growth and viability of bifidobacteria in dairy products is a major challenge to dairy producers because of the inability of certain strains to grow and survive in milk. In order to investigate methods for improving the viability of bifidobacteria in commercial products, the viability status of these microorganisms was surveyed in real milk media and a model medium of synthetic broth. Thus, the influence of different kinds of substrates on the survival and acidification ability of Bifidobacterium spp. during cold storage was tested.

\section{Materials and Methods}

\subsection{Bacterial Strains}

The list of potentially probiotic bifidobacterial strains used in this study is shown in Table 1 and were provided by Prof. Vlková (Czech University of Life Sciences, Prague, Czech Republic).

The sub-cultivation of bifidobacteria was performed in serum bottles in Wilkins-Chalgren (WCH) broth (Oxoid, Czech Republic) according to Rada and Petr [14], supplemented with $5 \mathrm{~g} / \mathrm{L}$ of soya peptone (Oxoid, Czech Republic), Tween-80 (1 mL/L; Biolofe, Italy), and Cysteine hydrochloride ( $0.5 \mathrm{~g} / \mathrm{L}$; Sigma-Aldrich Chemie $\mathrm{GmbH}$, Switzerland) was added to act as an oxygen scavenger to provide a low redox potential. Bifidobacterial strains were stored in $\mathrm{WCH}$ broth added with glycerol $(20 \% v / v)$ before using it as an inoculum (stored at $-20^{\circ} \mathrm{C}$ ).

Table 1. Origin of tested Bifidobacterium spp.

\begin{tabular}{cl}
\hline \multicolumn{1}{c}{ Bifidobacterium spp. } & \multicolumn{1}{c}{ Origin } \\
\hline B. animalis subsp. lactis DSM 10140 & Collection strain DSMZ \\
B. animalis subsp. animalis DSM 20104 & Collection strain DSMZ \\
B. thermophilum DSM 20212 & Collection strain DSMZ \\
B. animalis subsp. animalis 805 III2 & Feces of calf \\
B. thermophilum 17 III2 & Feces of calf \\
B. choerinum K1/1 & Feces of goat \\
B. pseudolongum K4/4 & Feces of goat \\
B. choerinum J14V & Feces of lamb \\
B. animalis subsp. animalis J5IIA & Feces of lamb \\
B. animalis subsp. animalis J3II & Feces of lamb \\
\hline
\end{tabular}

DSMZ-Deutsche Sammlung von Mikroorganismen und Zellkulturen, Germany. 


\subsection{Substrate Inoculation and Conditions of Cultivation}

Milk medium was prepared from reconstituted milk (14\% fat content; Bohemilk, Opocno, Czech Republic) according to the producer's instructions. Then, 100-mL aliquots were distributed into flasks, covered with lids, and boiled for $30 \mathrm{~min}$. Subsequently, flasks were cooled down and tempered to $37 \pm 0.5^{\circ} \mathrm{C}$. The standard suspension of the microorganisms was prepared by overnight incubation at $37 \pm 0.5^{\circ} \mathrm{C}$ and used in the individual experiments for inoculation of pre-tempered reconstituted milk, ultra-high-temperature (UHT) milk (1.5\% fat content; Meggle, Bratislava, Slovakia), and modified WCH broth (added with soya peptone, Tween, and cysteine hydrochloride (see Section 2.1)) at an initial concentration of about $10^{7} \mathrm{CFU} / \mathrm{mL}$. The sterility of milk samples was regularly confirmed by the plating method prior to the inoculation. The fermentation process was carried out aerobically for $24 \mathrm{~h}$ at $37 \pm 0.5{ }^{\circ} \mathrm{C}$, followed by a storage period $\left(6 \pm 0.5^{\circ} \mathrm{C}\right)$ within four weeks.

\subsection{Enumeration of Bifidobacteria and Determination of Active Acidity}

At appropriate time intervals, serial ten-fold dilutions of samples were prepared in a solution consisting of tryptone (5 g/L; Oxoid, Brno, Czech Republic), nutrient broth no. 2 (5 g/L; Oxoid, Brno, Czech Republic), yeast extract (2.5 g/L; Oxoid, Brno, Czech Republic), Tween-80 (0.5 mL/L), and cysteine hydrochloride $(0.25 \mathrm{~g} / \mathrm{L})$. Bifidobacteria were cultivated and enumerated on a selective transoligosaccharide propionate medium with added mupirocin (TOS-MUP) (Merck, Darmstadt, Germany) recommended by the International Dairy Federation [15]. Petri dishes were cultivated at $37 \pm 0.5^{\circ} \mathrm{C}$ for $72 \mathrm{~h}$ under anaerobic conditions using anaerobic jars and an Anaerocult A system (Merck, Darmstadt, Germany).

After incubation, the grown colonies were counted, and the results were converted into colony-forming units per $1 \mathrm{~mL}$ of the sample. The $\mathrm{pH}$ values of the samples were monitored during fermentation and storage using a $\mathrm{pH}$ meter with a penetration electrode (Knick Portamess, Berlin, Germany) calibrated with buffers at pH 4.0, 7.0, and 10.0 (Fisher Scientific, UK).

\subsection{Data Modeling}

The growth parameters of studied bifidobacteria were fitted and calculated using the mechanistic model "DMFit" by Baranyi and Roberts [16], incorporated in the DMFit tools kindly provided by Dr. J. Baranyi (University of Debrecen, Debrecen, Hungary). The growth function of Baranyi and Roberts expressed in the explicit form was applied as follows:

$$
y(t)=y_{0}+\mu_{\max } A(t)-\frac{1}{m} \ln \left(1+\frac{e^{m \mu_{\max } A(t)}-1}{e^{m\left(y_{\max }-y_{0}\right)}}\right)
$$

where $y(t)$ is the natural logarithm of the cell concentration, $y_{0}$ is the natural logarithm of the cell concentration at $t=t_{0}, t$ is time, $t_{0}$ is initial time of the growth, $\mu_{\max }$ is the maximum specific growth rate, $m$ is the curvature parameter to characterize the transition from the exponential phase (suggested values $m$ running from 1 to 10$), y_{\max }$ is the natural logarithm of the maximum cell concentration, and $A(t)$ is the function that plays the role of a gradual delay in time.

$$
A(t)=t+\frac{\ln \left(e^{-m \mu_{\max } t}+e^{-h_{0}}-e^{-v t-h_{0}}\right)}{\mu_{\max }}
$$

where $t$ is the time, $h_{0}$ is the dimensionless parameter quantifying the initial physiological state of the cells, and $v$ is the curvature parameter for characterization of the transition to the exponential phase.

The criterion for "goodness of fit" is the percent variance accounted for $(\% V)$ and was calculated according to Equation (3) [17]. 


$$
\% V=\left[1-\frac{\left(1-r^{2}\right)(n-1)}{\left(n-n_{T}-1\right)}\right] \times 100
$$

where $n$ is number of observations in the dataset, $n_{T}$ is the number of terms, and $r^{2}$ is the multiple regression coefficient.

Each experiment was performed in two separate trials. Statistical analyses were carried out using Microsoft Excel 2013 (Microsoft, Redmond, Washington, USA), with the addition of an analytical program Analyse-it (Analyse-it Software, Leeds, United Kingdom). The data were analyzed by the two-sided Tukey's post hoc test for means and Kruskal-Wallis test for medians of bifidobacteria as a group against substrates with a significance level of 0.05 .

\section{Results and Discussion}

The most important factor in developing technology for the production of probiotic foodstuffs is growth and viability of applied strains. Although bifidobacteria are considered more susceptible to oxygen compared to lactobacilli due to their anaerobic nature, the oxygen sensitivity of microorganisms from the genus Bifidobacterium may, however, be strain-dependent [10]. Thus, the changes in viable cells of bifidobacteria under aerobic conditions during growth and survival of studied substrates were evaluated. Within $1 \%(v / v)$ concentration of tested bifidobacterial strains, an increase in bacterial counts under aerobic conditions of about $1-2 \log \mathrm{CFU} / \mathrm{mL}\left(24 \mathrm{~h}, 37^{\circ} \mathrm{C}\right)$ was observed. Generally, different substrates determined almost the same maximum population densities after $24 \mathrm{~h}$, ranging within the average values of $8.96 \pm 0.43 \log \mathrm{CFU} / \mathrm{mL}(V=4.8 \%), 8.87 \pm 0.52 \log \mathrm{CFU} / \mathrm{mL}(V=5.9 \%)$, and $8.75 \pm 0.54 \log \mathrm{CFU} / \mathrm{mL}(V=6.2 \%)$ in reconstituted milk, UHT milk, and WCH broth, respectively. This statement was confirmed by Tukey's post hoc test, where mean differences were not significantly different $(p>0.05)$ within bifidobacteria and substrates tested.

High numbers of bifidobacteria may be attributed to the capability of tested microorganisms to detoxify oxygen as reported by Shimamura et al. [18]. Oxygen-tolerant bifidobacteria were also

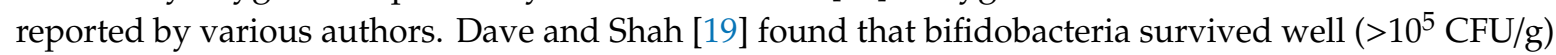
over a 35-day period in yoghurt, regardless of the oxygen content and redox potential of the yoghurt. Shimakama et al. [20] also reported that B. breve strain Yakult needed about $12 \mathrm{~h}$ to reach the stationary phase with counts of $10^{9} \mathrm{CFU} / \mathrm{mL}$ (from about $5 \times 10^{7} \mathrm{CFU} / \mathrm{mL}$ ). B. longum and B. bifidum in soymilk in a study of Kamaly [21] increased their populations by about 1.8 and 2.4 log orders, whereas the corresponding values attained in reconstituted skimmed milk were 2.5 and $2.7 \log \mathrm{CFU} / \mathrm{mL}$.

All fermented milks can be considered a suitable food matrix for probiotic bacteria supplementation, and values of 6-7 $\log \mathrm{CFU} / \mathrm{mL}$ (or $/ \mathrm{g}$ ) at the expiration date of final products are reported as adequate for providing positive effects on health of consumers [22]. In our study, the behavior of microorganisms during storage was not significantly $(p>0.05)$ affected by the bifidobacterial strains and media used, as analyzed by the Kruskal-Wallis test (Table 2). Generally, no remarkable variations $(p>0.05)$ in modified WCH broth within 28 days were found (final concentration varied from 8.26 to 9.98 log $\mathrm{CFU} / \mathrm{mL}$ at the end of the cold storage period) (Figure 1). This fact can be explained due to the presence of easily fermentable glucose, yeast extract, purines, pyrimidines, and amino acids supplying the nutritive elements required for the growth and survival of bifidobacteria. Counts of B. adolescentis Int57 in a study of Wu et al. [23] were also well maintained above $7 \log$ CFU/mL after $168 \mathrm{~h}$ in modified de Man, Rogosa and Sharpe (MRS) medium. According to Maganha et al. [24], bifidobacteria may be better cultivated on artificial media (WCH broth) than in milk. However, these media are expensive for bifidobacteria multiplication, and the excessive growth of such bacteria may provide unpleasant flavors of final products. Thus, the improvement of the conditions for the growth of bifidobacteria in fermented milk may be obtained by the addition of a nitrogen source (milk powder) or of substances that reduce the redox potential of the food matrix. Therefore, the next part of this study details the behavior of bifidobacteria in milk media (reconstituted and UHT milk). 
In reconstituted milk, a slight decrease in counts of bifidobacteria within the storage period was noted (0.12-0.81 log units), depending on the strain tested. Nonetheless, a clear significant decrease in the viability of $B$. thermophilum 17 III2 during the cold storage of fermented reconstituted milk was recorded (4.2 $\log \mathrm{CFU} / \mathrm{mL}$ ); a fast decline was neither observed in UHT milk nor modified WCH broth. Despite the decline in levels of B. thermophilum 17 III2, the counts did not drop below the limit of $10^{5} \mathrm{CFU} / \mathrm{mL}$, the minimum level suggested by some authors [25]. Also, lactobacilli in 10 commercial fermented milks in a study of Gueimonde et al. [26] were well maintained above $10^{5} \mathrm{CFU} / \mathrm{mL}$ during the cold storage period (30 days). In our study, in reconstituted fermented milk, a slight increase in counts of $\mathrm{K} 1 / 1$ isolate $(0.034 \log \mathrm{CFU} / \mathrm{mL} / \mathrm{h})$ within the storage period was observed, with almost the highest counts reached at the end of the cold storage phase $(9.2 \log \mathrm{CFU} / \mathrm{mL})$. The positive effect of reconstituted milk on high densities of bifidobacteria within storage could be attributed to the compact matrix and the buffering capacity of fermented milk media [27]. Maganha et al. [24] also observed a positive effect of the addition of milk powder on levels of B. animalis subsp. lactis, where counts ranged from 6.03 to $6.61 \log \mathrm{CFU} / \mathrm{mL}$ during storage within 21 days. Counts of Bifidobacterium spp. in UHT milk in our study ranged from 8.04 to $9.63 \log \mathrm{CFU} / \mathrm{mL}$ (Table 2) after $24 \mathrm{~h}$ with increased values after 28 days in DSM 10140, K1/1, and J5IIA strains. In this medium, the fastest reduction in the J3II strain was observed ( $-0.026 \log \mathrm{CFU} / \mathrm{mL} / \mathrm{h})$. Baron et al. [28] demonstrated that the survival of microorganisms from the genus Bifidobacterium spp. in fermented milks is strain-dependent, which is in agreement with our study. Considering the high heterogeneity of microorganisms, the composition of an ideal cultivation medium may vary. Currently, the origin of probiotics from the human gastrointestinal tract intended for human consumption is not an essential criterion. Zielińska and Kolozyn-Krajewska [29] showed that several microorganisms found in consumed food products do not originate from human hosts, e.g., B. animalis subsp. lactis and Saccharomyces cerevisiae var. boulardii.

Table 2. Parameters evaluating behavior of Bifidobacterium spp. during 28 days of cold storage $\left(6 \pm 1^{\circ} \mathrm{C}\right)$.

\begin{tabular}{|c|c|c|c|c|c|c|c|c|c|}
\hline \multirow{2}{*}{ Microorganism } & \multicolumn{3}{|c|}{ Reconstituted Milk } & \multicolumn{3}{|c|}{ Ultra-high-temperature Milk } & \multicolumn{3}{|c|}{ Wilkins-Chalgren Broth } \\
\hline & $\mathbf{N}_{24}$ & $\mathbf{N}_{\text {end }}$ & $\mathbf{k}_{\mathrm{d}}$ & $\mathbf{N}_{24}$ & $\mathbf{N}_{\text {end }}$ & $\mathbf{k}_{\mathrm{d}}$ & $\mathbf{N}_{24}$ & $\mathbf{N}_{\text {end }}$ & $\mathbf{k}_{\mathrm{d}}$ \\
\hline $\begin{array}{l}\text { B. animalis subsp. lactis } \\
\text { DSM } 10140\end{array}$ & $9.15^{*}$ & $8.72 *$ & $-0.001 *$ & $8.34 *$ & $9.15^{*}$ & $0.019^{*}$ & $9.40 *$ & $9.40 *$ & - \\
\hline $\begin{array}{l}\text { B. animalis subsp. lactis } \\
\text { DSM } 20104\end{array}$ & $8.79 *$ & $7.98^{*}$ & -0.003 * & $9.46^{*}$ & $7.46^{*}$ & $-0.002 *$ & $9.79 *$ & $9.98 *$ & $0.001 *$ \\
\hline B. thermophilum DSM 20212 & $8.01 *$ & $7.91 *$ & $-0.003 *$ & $8.83 *$ & $7.62 *$ & $-0.002 *$ & $8.00 *$ & $8.45 *$ & $0.001 *$ \\
\hline $\begin{array}{l}\text { B. animalis subsp. animalis } \\
\qquad 805 \mathrm{III} 2\end{array}$ & $9.32 *$ & $9.18^{*}$ & $0.001 *$ & $8.59 *$ & $8.15^{*}$ & -0.001 * & $8.83 *$ & $8.97^{*}$ & 0.00 * \\
\hline B. thermophilum 17 III2 & $9.28 *$ & $5.04 *$ & $-0.009 *$ & $9.63 *$ & $9.15^{*}$ & $-0.004 *$ & $9.90 *$ & $9.93 *$ & - \\
\hline B. choerinum K1/1 & $8.97 *$ & $9.20 *$ & $0.034 *$ & $8.35 *$ & $8.50 *$ & $0.001 *$ & $9.00 *$ & $9.26 *$ & $0.001 *$ \\
\hline B. pseudolongum $\mathrm{K} 4 / 4$ & $8.82 *$ & $8.61 *$ & $-0.002 *$ & $9.23 *$ & $8.91 *$ & $0.000 *$ & $8.95^{*}$ & $8.90 *$ & $-0.001 *$ \\
\hline B. choerinum $\mathrm{J} 14 \mathrm{~V}$ & $9.32 *$ & $8.74 *$ & $-0.005 *$ & $8.04 *$ & $7.04 *$ & $-0.001 *$ & $8.92 *$ & $8.85 *$ & $-0.001 *$ \\
\hline B. animalis subsp. animalis J5IIA & $9.35 *$ & $9.20 *$ & $-0.001 *$ & $8.76^{*}$ & $9.34 *$ & $0.012 *$ & $8.43^{*}$ & $8.26^{*}$ & $-0.038 *$ \\
\hline B. animalis subsp. animalis J3II & $8.85^{*}$ & $8.69 *$ & - & $9.48^{*}$ & $5.78^{*}$ & $-0.026^{*}$ & $8.47^{*}$ & $8.98^{*}$ & $0.004 *$ \\
\hline Medians for all bifidobacteria & $9.06^{* *}$ & $8.71 * *$ & $0.002 * *$ & $8.80^{* *}$ & $8.33^{* *}$ & $0.001^{* *}$ & $8.94^{* *}$ & $8.98 * *$ & $0.001 * *$ \\
\hline
\end{tabular}




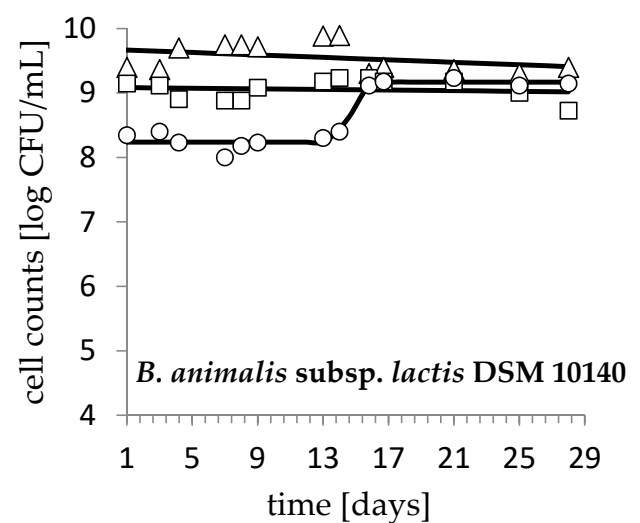

(a)

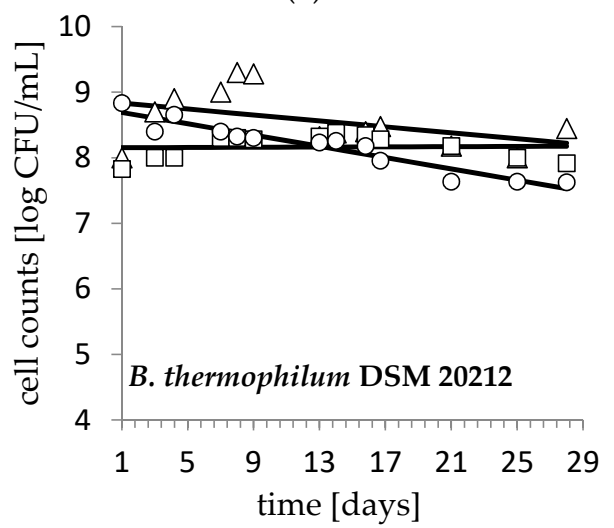

(c)

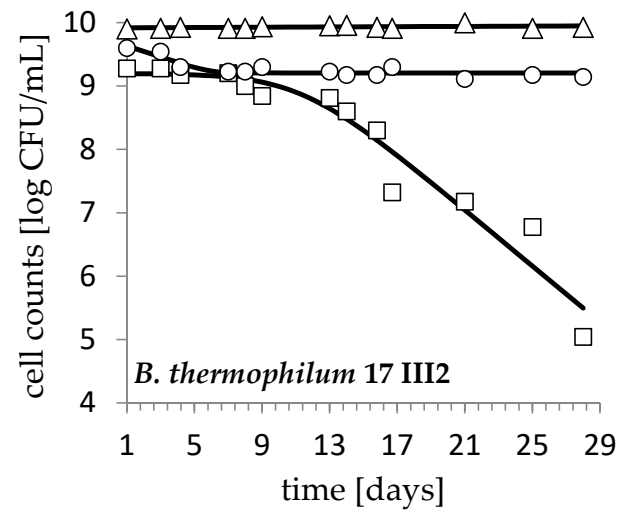

(e)

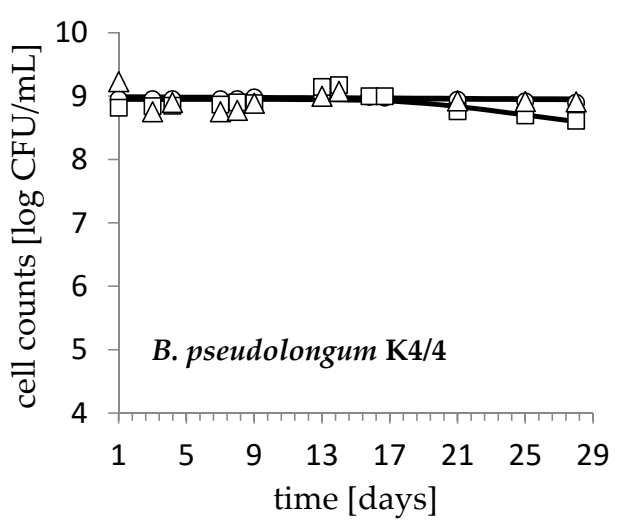

(g)

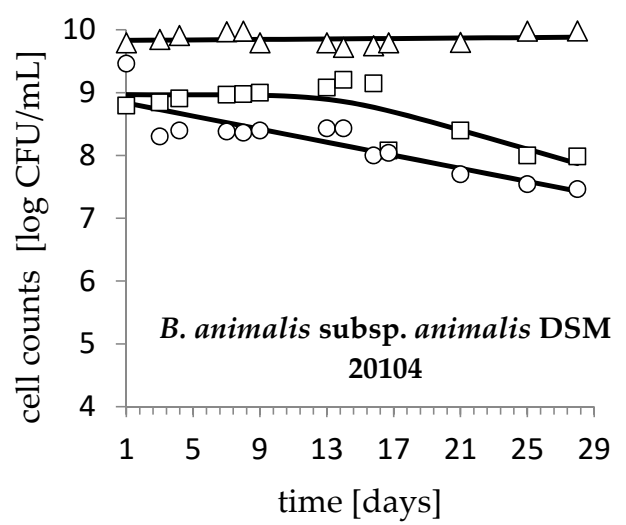

(b)

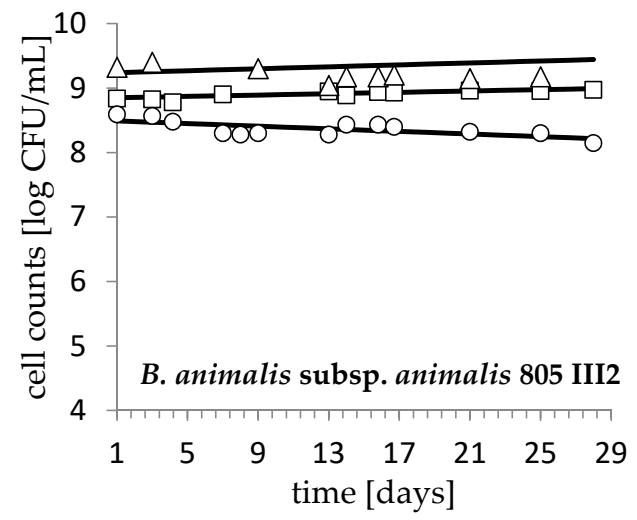

(d)

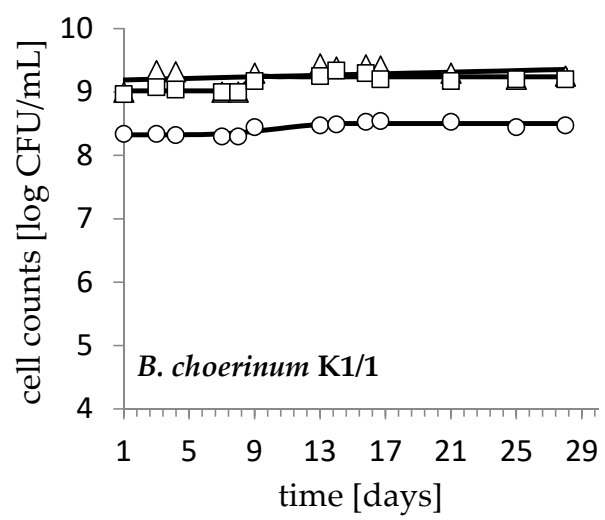

(f)

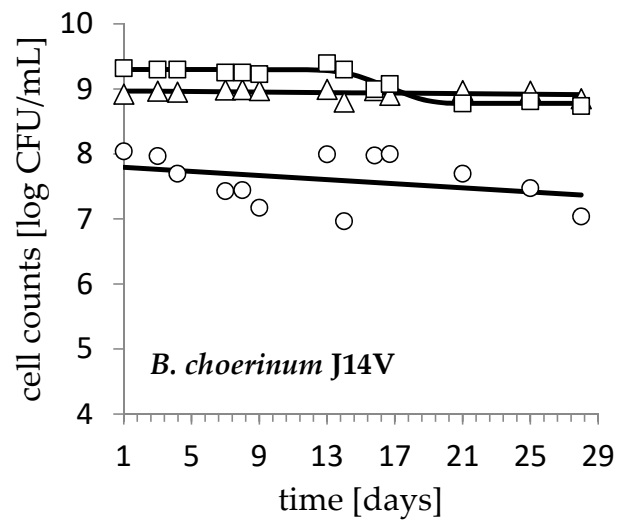

(h)

Figure 1. Cont. 


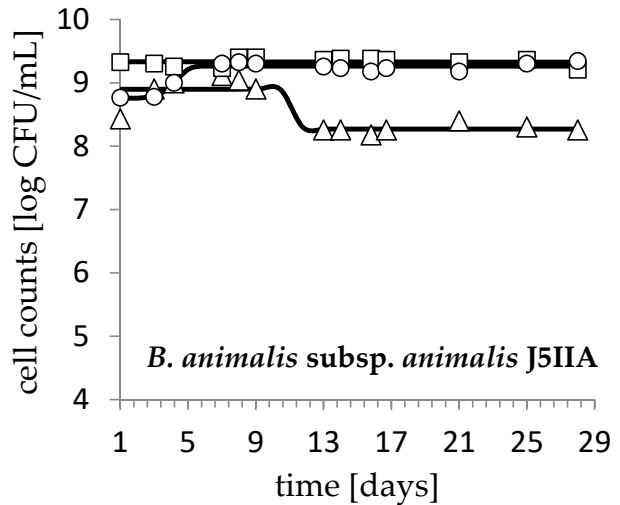

(i)

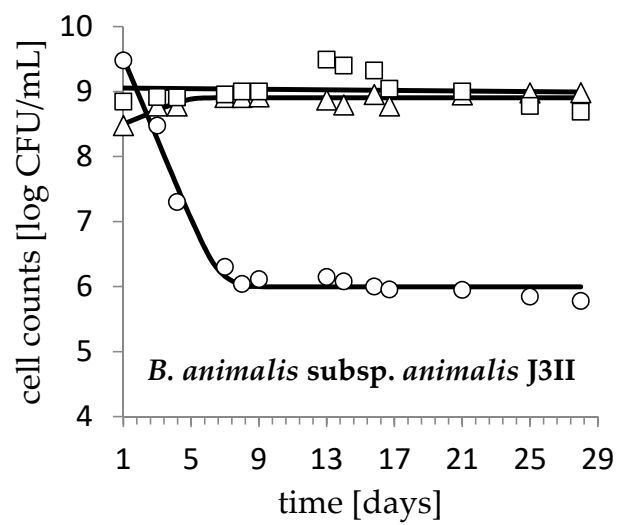

(j)

Figure 1. Survival of bifidobacteria in modified Wilkins-Chalgren $(\mathrm{WCH})$ broth $(\Delta)$, fermented reconstituted milk $(\square)$, and fermented ultra-high-temperature (UHT) milk $(\bigcirc)$ in B. animalis subsp. lactis DSM 10140 (a) B. animalis subsp. animalis DSM 20104 (b) B. thermophilum DSM 20212 (c) B. animalis subsp. animalis 805 III2 (d) B. thermophilum 17 III2 (e) B. choerinum K1/1 (f) B. pseudolongum K4/4 (g) B. choerinum J14V (h) B. animalis subsp. animalis J5IIA (i) B. animalis subsp. animalis J3II (j) strains at $6{ }^{\circ} \mathrm{C}$ within four weeks.

To precisely evaluate the fermentation ability, in addition to measuring bacterial density, it is important to analyze the changes in the active acidity of growth media. Changes in media fermentation involve the conversion of carbohydrates to organic acids, resulting in a reduction in $\mathrm{pH}$ values. Rapid acidification is a priority for the development of starter cultures for fermented milk products [30]. Despite this fact, the growth and acid production of probiotic bacteria in milk is usually too slow to support an adequate fermentation process [9]. Matejčeková et al. [31] reported no significant changes in active acidity (0.00-0.24 units) in the L. plantarum HM1 strain during growth and multiplication in milk. Negligible acid production was also recorded in a study of Valík et al. [32] in L. rhamnosus GG in milk. This is not in agreement with our results, where, for all samples analyzed, there was a fast decrease in $\mathrm{pH}$ within $24 \mathrm{~h}$ (data not shown). The $\mathrm{pH}$ decrease during the fermentation of dairy products affects a number of aspects of the manufacturing process, including the quality, texture, and composition of the products [33]. In WCH broth, a decrease of about 1.58-2.13 units was recorded, with final $\mathrm{pH}$ varying from 4.60 to 4.90 after 28 days (Figure 2). These results are equivalent to the rate constant for a decrease of $\mathrm{pH}\left(k_{p H}\right)$ that varied from -0.08 to $-0.14 \mathrm{~h}^{-1}$. Krausova et al. [34] recorded a decrease in WCH broth from 6.40 to 4.69 on average in six lactobacilli strains and B. bifidum JKM. During the growth and multiplication at $37^{\circ} \mathrm{C}$, comparable $\mathrm{pH}$ changes of about $0.98-2.12$ and 0.80-2.02 were observed in UHT and reconstituted milk, respectively. Similar observations in $\mathrm{pH}$ changes were reported in soymilk as an appropriate growth medium for lactic acid bacteria [21]. In our study, in UHT and reconstituted milk, final $\mathrm{pH}$ values at the end of 28 days of storage varied from 4.5 to 5.5 and from 4.5 to 5.4 , respectively. Despite the low $\mathrm{pH}$ values that may affect the viability of tested microbes, bifidobacteria in our study survived in concentrations $>5 \log \mathrm{CFU} / \mathrm{mL}$ as stated previously. Regarding the shelf stability of samples analyzed, the post-acidification study is an important step since it reflects metabolic behavior of microbes used [35]. As seen in Figure 2, all samples analyzed followed an almost linear pattern within the storage period, except the DSM 20104 strain in reconstituted milk. In this strain, the $\mathrm{pH}$ reached after the fermentation (5.7) still decreased by about 0.19 units during storage with the rate of $-0.05 \mathrm{~h}^{-1}$ (final counts $=7.98 \log \mathrm{CFU} / \mathrm{mL}$ ). The $\mathrm{pH}$ value of 4.5 is considered as a critical value in minimizing the outgrowth of the contaminating food spoilage and pathogenic bacteria. Generally, efficient acidification profiles are usually achieved when in co-culture [22]. Hence, further studies are required to assess the growth-promoting effects of co-cultivation with other strains of lactic acid bacteria used in dairy products. 


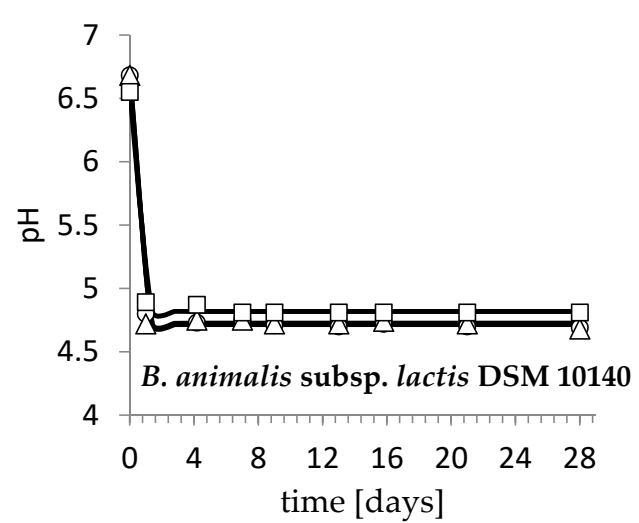

(a)

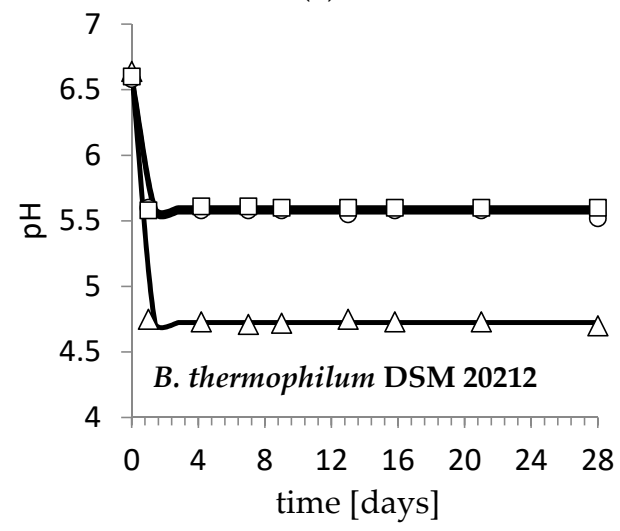

(c)

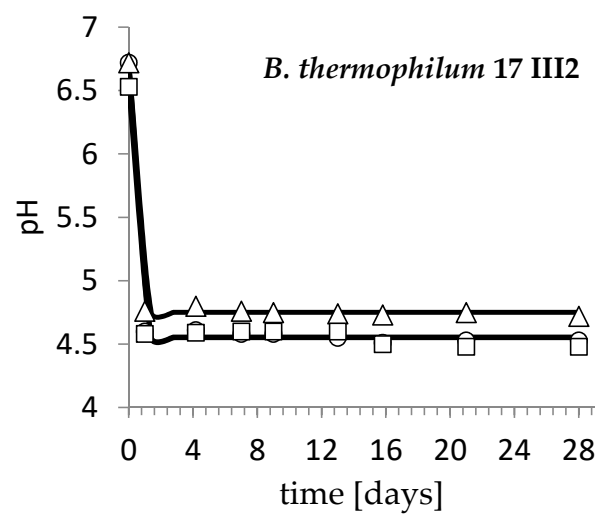

(e)

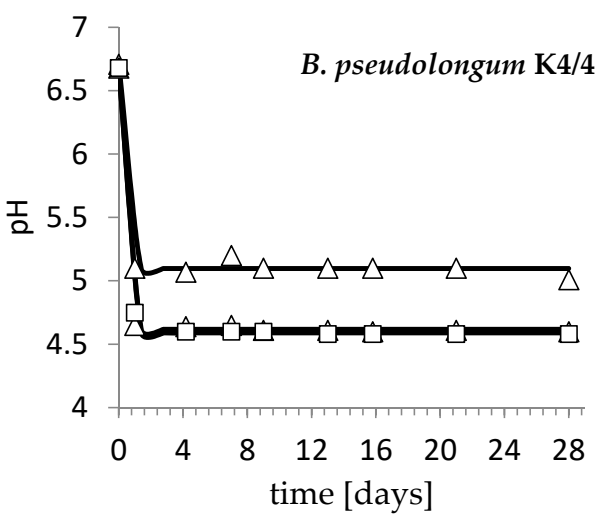

(g)

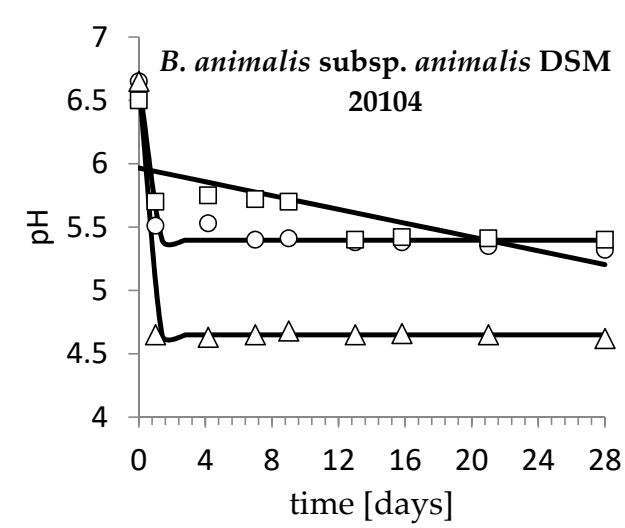

(b)

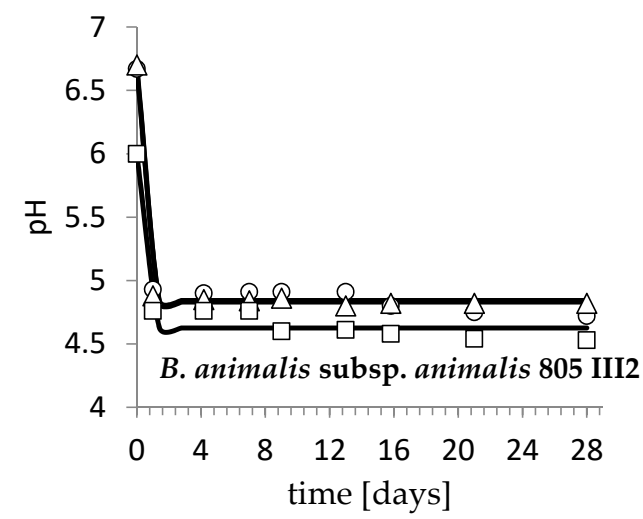

(d)

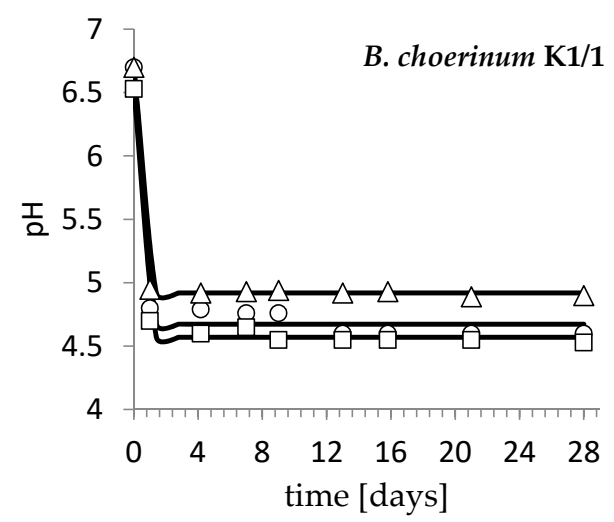

(f)

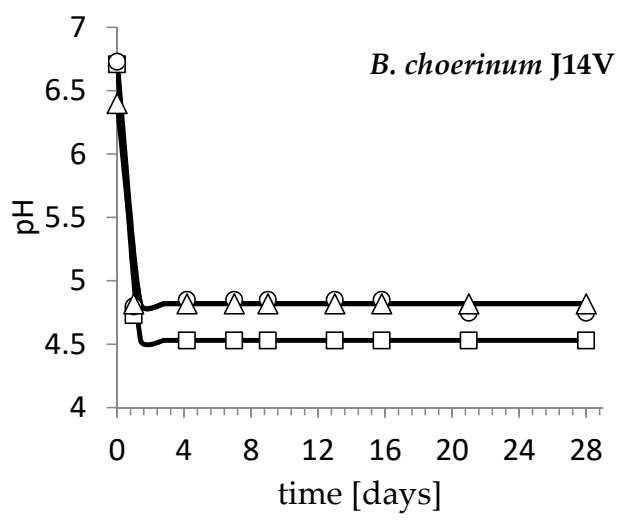

(h)

Figure 2. Cont. 


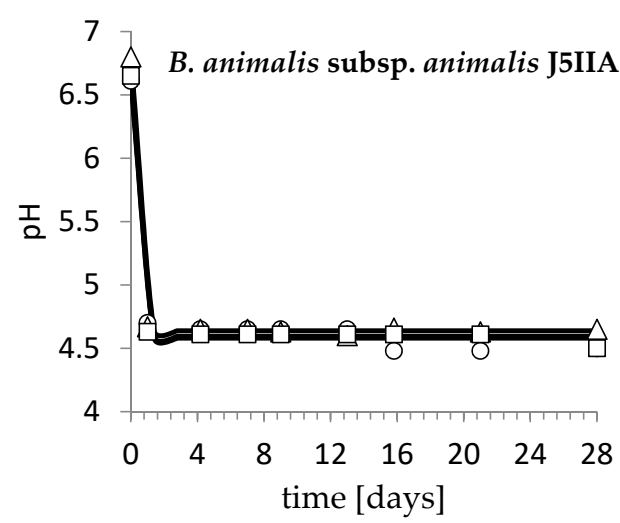

(i)

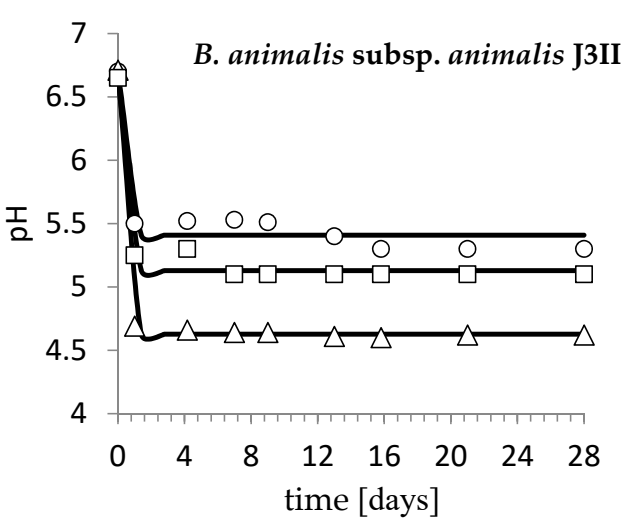

(j)

Figure 2. Changes in $\mathrm{pH}$ as a function of incubation time in modified $\mathrm{WCH}$ broth $(\Delta)$, fermented reconstituted milk ( $\square$ ), and fermented UHT milk $(\bigcirc)$ in B. animalis subsp. lactis DSM 10140 (a) B. animalis subsp. animalis DSM 20104 (b) B. thermophilum DSM 20212 (c) B. animalis subsp. animalis 805 III2 (d) B. thermophilum 17 III2 (e) B. choerinum K1/1 (f) B. pseudolongum K4/4 (g) B. choerinum J14V (h) B. animalis subsp. animalis J5IIA (i) B. animalis subsp. animalis J3II (j) strains at $6{ }^{\circ} \mathrm{C}$ within four weeks.

\section{Conclusions}

Since the growth responses of bifidobacteria are substrate- and oxygen-dependent, it is necessary to study the growth dynamic and viability of specific strains. Considering different types of products containing bifidobacteria available for Slovak consumers, experiments were realized in an artificial modified medium of WCH broth and in real media of reconstituted and ultra-pasteurized milk. Growth of 10 different species of bifidobacteria originating from the intestinal tract of animals and collection strains were studied in vitro under aerobic conditions. Maximal counts were generally achieved in $\mathrm{WCH}$ broth at the end of storage period at $6{ }^{\circ} \mathrm{C}$ for 28 days (from 8.26 to $9.98 \log \mathrm{CFU} / \mathrm{mL}$ ). The results of our study also indicate that the milk media used may serve as an excellent vehicle for dietary incorporation of Bifidobacterium cells. The results obtained may help optimize fermentation processes in dairy practice to provide reliable carriers of bifidobacteria for consumers.

Author Contributions: Z.M. performed the experiments, analyzed the data, and wrote the paper; E.V. provided microorganisms and set up the methodology; D.L. revised the manuscript and approved the final version for publication; L'.V. supervised and provided his expert comments within manuscript preparation.

Funding: This research was funded by the Scientific Grant Agency of the Ministry of Education of the Slovak Republic Vega No. 1/0363/19.

Acknowledgments: The authors are thankful to Marek Lelovský for English language corrections.

Conflicts of Interest: The authors declare no conflict of interest.

\section{References}

1. Awasti, N.; Tomar, S.K.; Pophaly, S.D.; Poonam, V.K.; Singh, T.P.; Anand, S. Probiotic and functional characterization of bifidobacteria of Indian human origin. J. Appl. Microbiol. 2015, 120, 1021-1032. [CrossRef] [PubMed]

2. Bunešová, V.; Vlková, E.; Rada, V.; Killer, J.; Musilova, S. Bifidobacteria from the gastrointestinal tract of animals: Differences and similarities. Benefic. Microbes 2014, 5, 377-388. [CrossRef]

3. Delcenserie, V.; Gavini, F.; Beerens, H.; Tresse, O.; Franssen, C.; Daube, G. Description of a new species, Bifidobacterium crudilactis sp. Nov., isolated from raw milk and raw milk cheeses. Syst. Appl. Microbiol. 2007, 30, 381-389. [CrossRef] [PubMed]

4. Dong, X.Z.; Xin, Y.H.; Jian, W.Y.; Liu, X.L.; Ling, D.W. Bifidoabcterium thermacidophilum sp. nov., isolated from an anaerobic digester. Int. J. Syst. Evol. Microbiol. 2000, 50, 119-125. [CrossRef] 
5. Simpson, J.M.; Martineau, B.; Jones, W.E.; Ballam, J.M.; Mackie, R.I. Characterization of fecal bacterial populations in canines: Effects of age, breed and dietary fibre. Microb. Ecol. 2002, 44, 186-197. [CrossRef] [PubMed]

6. Jakubczak, A.; Stachelska, M.A.; Świstocka, R.; Lewandowski, W. The application of probiotic bacteria in the fermented vegetable cereal and meat products. Polish J. Nat. Sci. 2012, 27, 81-92.

7. Leahy, S.C.; Higgins, D.G.; Fitzgerald, G.F.; Sinderen, D. Getting better with bifidobacteria. J Appl Microbiol 2005, 98, 1303-1315. [PubMed]

8. Cronin, M.; Ventura, M.; Fitzgerald, G.F.; Sinderen, D. Progress in genomics, metabolism and biotechnology of bifidobacteria. Int. J. Food Microbiol. 2011, 149, 4-18. [CrossRef]

9. Shah, N.P. Probiotic bacteria: Selective enumeration and survival in dairy foods. J. Dairy Sci. 2000, 83, 894-907. [CrossRef]

10. Talwalkar, A.; Kailasapathy, K. The role of oxygen in the viability of probiotic bacteria with reference to $L$. acidophilus and Bifidobacterium spp. Current Issues Int. Microbiol. 2004, 5, 1-8.

11. Kawasaki, S.; Mimura, T.; Satoh, T.; Takeda, K.; Niimura, Y. Response of the microaerophilic Bifidobacterium species, B. boum and B. thermophilum, to oxygen. Appl. Environ. Microbiol. 2006, 72, 6854-6858. [CrossRef]

12. Lamoureux, L.; Roy, D.Y.; Gauthier, S.F. Production of oligosachcarides in yogurt containing bifidobacteria and yogurt cultures. J. Dairy Sci. 2002, 85, 1058-1069. [CrossRef]

13. Havas, P.; Kun, S.; Perger-Mészáros, I.; Rezseey-Szabó, J.M.; Nguyen, Q.D. Performances of new isolates of Bifidobacterium on fermentation of soymilk. Acta Microbiol. et Imunol. Hung. 2015, 62, 463-475. [CrossRef]

14. Rada, V.; Petr, J. A new selective medium for the isolation of glusoce non-fermenting bifidobacteria from hen caeca. J. Microbiol. Methods 2000, 43, 127-132. [CrossRef]

15. Vlková, E.; Salmonová, H.; Bunešová, V.; Geigerová, M.; Rada, V.; Musilová, Š. A new medium containing mupirocin, acetic acid, and norfloxacin for the selective cultivation of bifidobacteria. Anaerobe 2015, 34, 27-33. [CrossRef] [PubMed]

16. Baranyi, J.; Roberts, A.T. Mathematics of predictive food microbiology. Int. J. Food Microbiol. 1995, 26, 199-218. [CrossRef]

17. Davey, K.R. Modelling the combined effect of temperature and $\mathrm{pH}$ on the rate coefficient for bacterial growth. Int. J. Food Microbiol. 1994, 23, 295-303. [CrossRef]

18. Shimamura, S.; Abe, F.; Ishibashi, N.; Miyakawa, H.; Yaeshima, T.A.; Tomita, M. Relationship between oxygen sensitivity and oxygen metabolism of Bifidobacterium species. J. Dairy Sci. 1992, 75, 3296-3306. [CrossRef]

19. Dave, R.I.; Shah, N.P. Viability of yoghurt and probiotic bacteria in yoghurts made from commercial starter cultures. Int. Dairy J. 1997, 7, 31-41. [CrossRef]

20. Shimakama, Y.; Matsubara, S.; Yuki, N.; Ikeda, M.; Ishikawa, F. Evaluation of Bifidobacterium breve strain Yakult-fermented soymilk as a probiotic food. Int. J. Food Microbiol. 2003, 81, 131-136. [CrossRef]

21. Kamaly, K.M. Bifidobacteria fermentation of soybean milk. Food Res. Int. 1997, 30, 675-682. [CrossRef]

22. Matejčeková, Z.; Liptáková, D.; Valík, L'. Functional probiotic products based on fermented buckwheat with Lactobacillus rhamnosus. LWT- Food Sci. Technol. 2017, 81, 35-41. [CrossRef]

23. Wu, Q.Q.; You, H.J.; Ahn, H.J.; Kwon, B.; Ji, G.E. Changes in growth and survival of Bifidobacterium by coculture with Propionibacterium in soy milk, cow‘s milk, and modified MRS medium. Int. J. Food Microbiol. 2012, 157, 65-72. [CrossRef] [PubMed]

24. Maganha, L.C.; Rosim, R.; Corassin, C.H.; Cruz, A.G.; Faria, J.; Oliviera, C. Viability of probiotic bacteria in fermented skim milk produced with different levels of milk powder and sugar. Int. J. Dairy Technol. 2014, 67, 89-94. [CrossRef]

25. Matejčeková, Z.; Soltészová, F.; Ačai, P.; Liptáková, D.; Valík, L'. Application of Lactobacillus plantarum in functional products based on fermented buckwheat. J. Food Sci. 2018, 83, 1053-1062. [CrossRef] [PubMed]

26. Gueimonde, M.; Delgado, S.; Mayo, B.; Ruas-Madiedo, P.; Margolles, A.; Reyes-Gavilán, C.G. Viability and diversity of probiotic Lactobacillus and Bifidobacterium populations included in commercial fermented milks. Food Res. Int. 2004, 37, 839-850. [CrossRef]

27. Shaffie, G.; Mortazavian, A.M.; Mohammadifar, M.A.; Koushki, M.R.; Mohammadi, A.R.; Mohammadi, R. Combined effects of dry matter content, incubation temperature and final $\mathrm{pH}$ of fermentation on biochemical and microbiological characteristics of probiotic fermented milk. Afr. J. Microbiol. Res. 2010, 4, 1265-1274.

28. Barona, M.; Roy, D.; Vuillemard, J. Biochemical characteristics of fermented milk produced by mixed-cultures of lactic starters and bifidobacteria. Lait 2000, 80, 465-478. [CrossRef] 
29. Zielińska, D.; Kolozyn-Krajewska, D. Food-origin lactic acid bacteria may exhibit probiotic properties: Review. BioMed Res. Int. 2018, 3, 1-15. [CrossRef]

30. Rathore, S.; Salmerón, I.; Pandiella, S. Production of potentially probiotic beverages using single and mixed cereal substrates fermented with lactic acid bacteria cultures. Food Microbiol. 2012, 30, 239-244. [CrossRef]

31. Matejčeková, Z.; Liptáková, D.; Spodniaková, S.; Valík, L'. Characterization of the growth of Lactobacillus plantarum in milk in dependence on temperature. Acta. Chim. Slovaca. 2016, 9, 104-108. [CrossRef]

32. Valík, L'; Medved'ová, A.; Liptáková, D. Characterization of the growth of Lactobacillus rhamnosus GG in milk at suboptimal temperature. J. Food Nutr. Res. 2008, 47, 60-67.

33. Liptáková, D.; Matejčeková, Z.; Valík, L'. Lactic acid bacteria and fermentation of cereals and pseudocereals. In Fermentation Processes; Jozala, A.F., Ed.; InTech: Rijeka, Croatia, 2017; Volume 3, pp. 223-254.

34. Krausova, G.; Rada, V.; Marsik, P.; Musilova, S.; Svejstil, R.; Drab, V.; Hyrslova, I.; Vlková, E. Impact of purified human milk oligosachcarides as a sole carbon source on the growth of lactobacilli in in vitro model. Afr. J. Microbiol. Res. 2015, 9, 565-571.

35. Campos, D.C.D.S.; Neves, L.T.B.C.; Flach, A.; Costa, L.A.M.A.; De Sousa, B.O. Post-acidification and evaluation of anthocyanins stability and antioxidant activity in acai fermented milk and yoghurts. Rev. Bras. Frutic. 2017, 39, 1-13. [CrossRef]

(C) 2019 by the authors. Licensee MDPI, Basel, Switzerland. This article is an open access article distributed under the terms and conditions of the Creative Commons Attribution (CC BY) license (http://creativecommons.org/licenses/by/4.0/). 